\title{
Sponsor Device Identifier
}

National Cancer Institute

\section{Source}

National Cancer Institute. Sponsor Device Identifier. NCI Thesaurus. Code C117060.

A sponsor-defined sequence of characters used to identify, name, or characterize the device. 